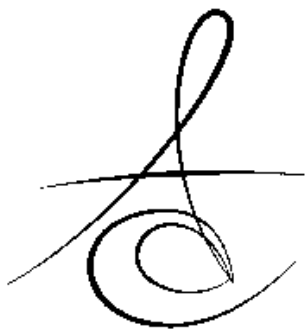

Makale Kodu/Article code: 1769

Makale Gönderilme tarihi: 08.07.2014

Kabul Tarihi: 18.11 .2014

\section{UNİKİSTİK AMELOBLASTOMA: OLGU SUNUMU ${ }^{*}$}

UNICYSTIC AMELOBLASTOMA: A CASE REPORT ${ }^{*}$

\author{
Yrd. Doç. Dr. Gonca DUYGU* Dt. Gül Merve YALÇIN*
}

Dr. Fatih CABBAR*

\section{ÖZET}

Ameloblastoma cinsiyet ayrımı gözetmeksizin genellikle genç yetişkinlerde izlenmektedir. Robinson ve Martinez tarafından 1977 yılında tanımlanan ve ameloblastomanın bir çeşidi olan unikistik ameloblastoma, klinik ve radyolojik olarak odontojenik bir kistin özelliklerine sahipken; histopatolojik olarak kistik kavite luminal ve/veya mural tümoral proliferasyon izlenen ya da izlenmeyen ameloblastik epitel özelliğindedir. Tüm intraosseöz ameloblastomanın \%5-15'ini oluşturur. Unikistik ameloblastoma solid yada multikistik tiplerine göre daha az agresif özellikte olup, konservatif cerrahi işlemlerle yeterli tedavi sağlanmaktadır. Bu vaka raporunda, 46 yaşında kadın hastanın posterior maksiller bölgesinde lokalize unikistik ameloblastomanın enükleasyon sonrasındaki iki yıllık takibi sunulmaktadır.

Anahtar Kelimeler: Unikistik Ameloblastoma, Maksilla, Kistik Lezyon, Oroantral Fistül

\section{ABSTRACT}

Unicystic ameloblastoma, a variant of ameloblastoma first described by Robinson and Martinez in 1977, refers to those cystic lesions that show clinical and radiologic characteristics of an odontogenic cyst but in histologic examination show a typical ameloblastomatous epithelium lining part of the cyst cavity, with or without luminal and/or mural tumor proliferation. It accounts for 5-15\% of all intraosseous ameloblastoma. Unicystic ameloblastoma is believed to be less aggressive and responds more favorably to conservative surgery than the solid or multicystic ameloblastomas. In this case report, we will present 2 years follow-up of a 46-year-old female with unicystic ameloblastoma in the posterior maxilla treated with enucleation.

Key words: Unicystic Ameloblastoma, Maxilla, Cystic Lesion, Oroantral Fistula

\section{GİRİş}

Unikistik Ameloblastoma (UA) ilk olarak 1977'de Robinson ve Martinez tarafından tanımlanmıştır 1 . Ameloblastoma'nın alt tipi olmasına rağmen, ameloblastomaya göre daha selim bir karaktere sahip olmakla birlikte, konservatif tedavilere daha iyi cevap vermesinden dolayı tedavi ve prognoz anlamında ameloblastomadan farklılık gösterebilir. Genellikle hayatın 2030 yaşlarındaki genç bireylerde ortaya çıkmakta ve ameloblastomaya benzer olarak 1:1,3 oranında erkek bireylerde daha fazla gözlenmektedir ${ }^{2-6}$. Solid ameloblastomalar ile başka bir benzerliği ise sıklıkla mandibular molarlar ve ramus bölgesinde lokalize olmasıdır. ${ }^{6}$
UA lezyonları, radyografik olarak incelendiğinde genellikle sınırları belirgin uniloküler radyolusent lezyonlar olarak gözlenmektedirler. Literatürde, vakaların yaklaşık \%50-80'inin gömülü bir dişle alakalı olduğu belirtilmiştir ${ }^{5}$. Bu sebepten dolayı, UA'nın radyolojik ve klinik olarak dentigeröz kistle ayırıcı tanısının yapılması zorlaşabilmektedir ${ }^{3-5}$.

UA histolojik olarak, ameloblastomatöz epitelin dağılımı ve bulunuş durumuna göre, luminal, intraluminal ve intramural olmak üzere üç sınıfa ayrılmaktadır 3. Bu histopatolojik sınıflamanın direk olarak lezyonun biyolojik durumu, tedavi seçenekleri ve tedavinin prognozuna etkisi bulunmaktadır.

$\mathrm{Bu}$ vaka raporunda, 46 yaşında bir kadın hastanın posterior maksiller bölgesinde lokalize

\footnotetext{
*Yeditepe Üniversitesi, Diş Hekimliği Fakültesi, Ağız Diş ve Çene Cerrahisi Anabilim Dalı

F Bu çalışma -7. Uluslararası ACBID kongresinde poster sunumu olarak bildirilmiştir.

29 Mayıs-2 Haziran 2013, Antalya-TÜRKİYE
}

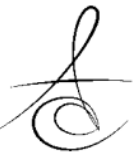


unikistik ameloblastomanın klinik, radyolojik ve histopatolojik bulguları ile birlikte enükleasyon sonrasındaki iki yıllık takibi sunulmaktadır.

\section{OLGU SUNUMU}

46 yaşındaki kadın hasta sağ posterior maksiller bölgesinde oroantral fistül şikayeti ile kliniğimize yönlendirilmiştir. Hastanın herhangi bir sistemik rahatsızlığı bulunmamaktadır. Yapılan ağız içi muayenede sağ posterior maksillada bir fistül bulunduğu ve bu fistülden herhangi bir drenaj olmadığı gözlenmiştir. Valsalva manevrasının sonucu negatif olmakla birlikte, hastanın tükettiği gıdalar burnundan gelmemektedir. Hastanın panoramik radyografisi incelendiğinde bölgede sınırları belirgin uniloküler radyolusent bir lezyon görülmüştür. Üç boyutlu BT görüntüsünde ise lezyon ile maksiller sinüs arasında kemik bulunduğu ve palatinal ve bukkal kemiğin ise intakt olduğu gözlenmiştir (Resim 1). Klinik ve radyolojik olarak yapılan incelemeler sonucunda lezyonun primer olarak rezidüel kist olabileceği belirtilirken, ayırıcı tanı olarak da unikistik ameloblastoma, keratokistik odontojenik tümör ve basit kemik kisti düşünülmüştür. Lezyon enükle edilmiş ve alınan eksizyonel biyopsi materyali histopatolojik inceleme için gönderilmiştir. Mikroskopik olarak Hematoksilen eozin ile yapılan (H\&E) boyamada intraluminal epitel proliferasyonu olduğu gözlenmiştir. Ki-67 (MIB-1) ile yapılan immunohistokimyasal incelemede ise, lezyonu çevreleyen epitel duvarında amelob- lastik hücrelerin varlığı saptanmıştır (Resim 2a,b). Böylece lezyonun son olarak histopatolojik tanısı intraluminal unikistik ameloblastoma olarak konmuştur.

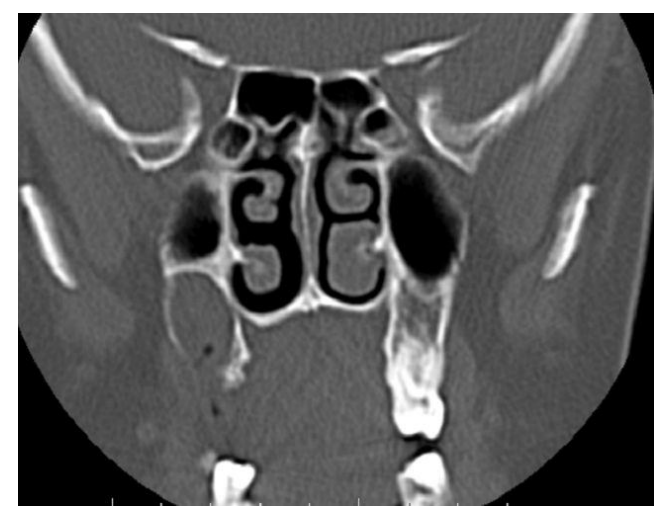

Resim 1. BT görüntüsünde lezyonu çevreleyen kemik intakttır.

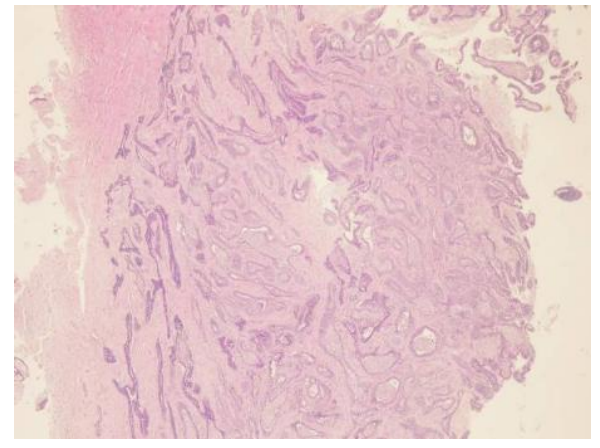

Resim 2a. Hematoksilen\&Eosin (H\&E) ile boyanan kesitte (x40) intraluminal epitel proliferasyonu gözlenmektedir.

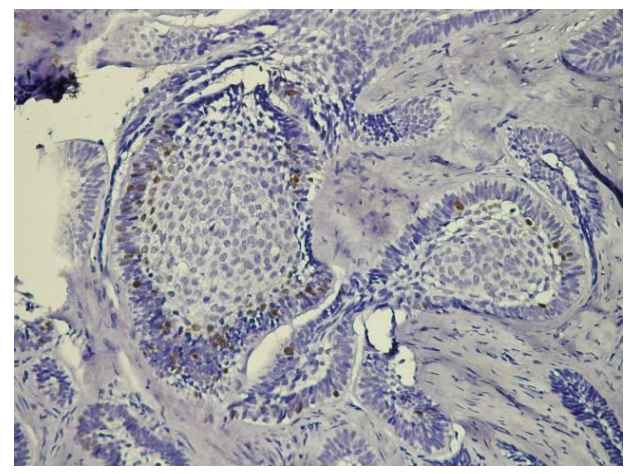

Resim 2b. Ki-67 (MIB-1) immunohistokimyasal görüntü (x200) kistik epitel duvarında bulunan ameloblastik hücreleri göstermektedir.

Hasta iki yıl boyunca klinik ve radyolojik olarak takip edilmiştir (Resim 3). İki yıl sonunda alınan BT ve panoramik radyografide herhangi bir rekürrens oluşumuna rastlanmamış ve yeni oluşan sağlıklı kemik izlenmiştir (Resim 4,5).

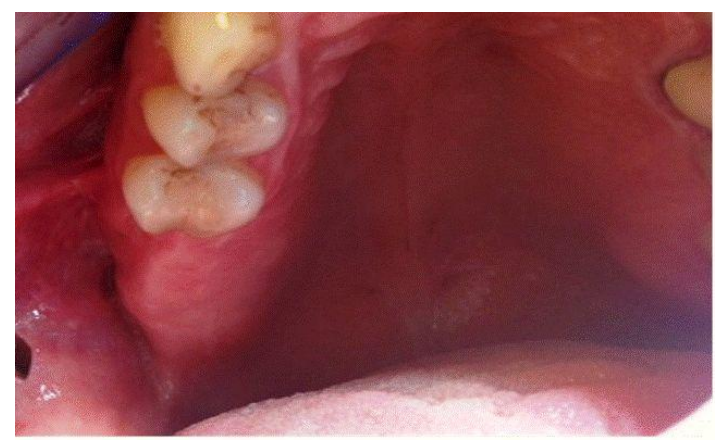

Resim 3. İki yıllık takip sonrasında alınan ağız içi görüntü bölgedeki mukoza sağlıklı gözükmektedir. 


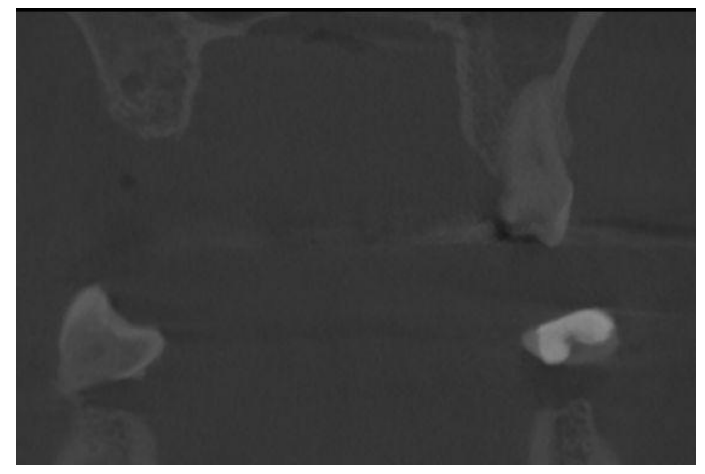

Resim 4. İki yıllık takipte, BT görüntüsünde herhangi bir özellik izlenmedi.

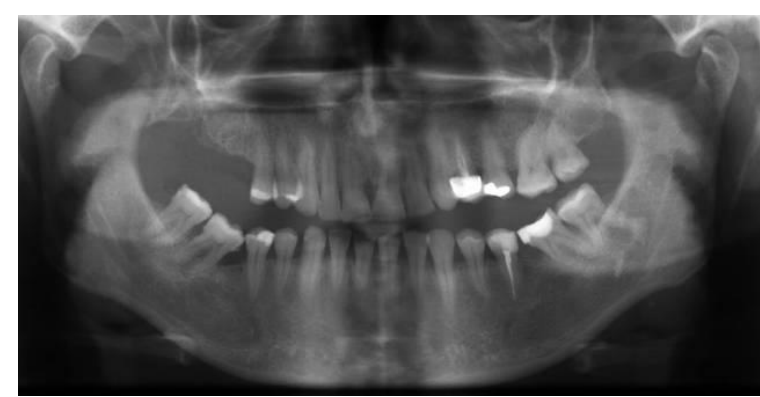

Resim 5. İki ylllık takipte, OPTG görüntüsünde herhangi bir özellik izlenmedi

\section{TARTIŞMA}

Ameloblastomalar çene kemiklerini etkileyen selim intraosseöz lezyonlardır. Diş gelişiminde rol oynayan mine epitelinden kaynaklandıkları düşünülmektedir ${ }^{7}$. Unikistik ameloblastoma, tüm ameloblastomlar arasında yaklaşık \%5-15 oranında gözlenmektedir. Diğer solid ameloblastomalara göre daha az agresif bir karakter gösteren bu lezyon, genellikle 2030 yaşlardaki genç bireylerde gözlenmektedir ve erkeklerde daha sıklıkla karşılaşılmaktadır. Klinik ve radyolojik olarak UA en çok mandibulada, angulus ve ramus bölgesinde ve genellikle gömülü bir yirmi yaş dişi ile birlikte sınırları belirgin radyolusent bir lezyon olarak karşımıza çıkmaktadır. Bu sebepten dolayı ayırıcı tanıda dentigeröz kist, adenomatoid odontojenik tümör ve keratokistik odontojenik tümör bulunmalıdır ${ }^{8}$. Bu çalışmada sunulan vakada ise lezyon unikistik ameloblastomanın genellikle gözlenmediği bir bölge olan posterior maksillada lokalize olduğundan dolayı, her iki çenede de gözlenen sınırları belirgin uniloküler radyolusent lezyonların ayırıcı tanısında mutlaka yer almalıdır.
UA'nın tedavisine ise histopatolojik tanıdan sonra karar verilmelidir. Günümüzde Ackermann ve arkadaşlarının yapmış olduğu sınıflama ve bu sınıflamanın modifikasyonları kullanılmaktadır. Bu sınıflamaya göre üç tip UA bulunmaktadır. Bunlardan ilki luminal UA'dır. Bu tip UA'da uniloküler kist boşluğunu döşeyen epitelin bazı bölgelerinde ameloblastik transformasyon gerçekleşmiştir ve bağ dokusuna herhangi bir infiltrasyon söz konusu değildir. İkinci grup ise; intraluminal UA'dır ve ilk gruptan farklı olarak bağ dokusu içine ameloblastik hücrelerinde bulunduğu epitelin infiltrasyonu söz konusudur. Son olarak üçüncü grup ise; intramural UA'dır ve bağ dokusu içerisinde amelobastik epitel hücrelerinden oluşan adacıklar bulunmaktadır. İntramural UA bu adacıkların kist epiteli ile bağlı olmaları (a) veya bağımsız olmalarına (b) göre iki alt gruba ayrılmaktadır (Resim 6). UA bu gruplardan sadece birinin histolojik özelliğine sahip olabileceği gibi, birden fazlasının da özelliğini taşıyabilir. Bu sebepten dolayı UA'nın luminal (grup 1); luminal-intraluminal (grup 1-2); luminal-intramural (grup 1-3) ve luminal-intraluminal-intramural (grup 12-3) olmak üzere dört alt grubu olduğu söylenebilir ${ }^{3,5}$.

UA'nın histolojik tipi klinik özelliklerini etkilediği gibi seçilmesi gereken tedavi seçeneğini de belirlemektedir. Yukarıda belirtilen dört grubun ilk ikisinde (grup 1 ve 1-2) küretaj ve enükleasyon gibi konservatif tedavi seçenekleriyle başarı sağlanmaktadır ${ }^{4,9}$. Ayrıca enükleasyon sonrasında Carnoy solüsyonunun uygulanabileceği ${ }^{10}$ veya likit nitrojen ile kriyoterapi ${ }^{11}$ yapılabileceğini de belirten literatürler bulunmaktadır. Geri kalan gruplarda ise yani intramural proliferasyonun mevcut olduğu durumlarda rezeksiyon önerilmektedir; fakat tedavi planı yapılırken tümör rezeksiyonu sonrasında bölgenin rekonstrüksiyonu ve hastanın yaşam kalitesi de düşünülmelidir. Bu sebepten dolayı her ne kadar rekürrens oranı rezeksiyondan fazla olsa da, bazı vakalarda enükleasyon ile birlikte Carnoy solüsyonunun uygulanması düşünülmelidir ${ }^{12,13}$.

Sunulan hastanın histopatolojik sonuçları intraluminal UA bulgularını desteklediğinden, uygulanan eksizyonel biyopsi sonrasında hasta takibe alınmıştır. Yapılan iki yıllık takip sonrasından rekürrens izlenmemiştir. UA posterior maksillada nadir gözlenen bir lezyondur ve bu tür kistik lezyonların klinik bulguları oroantral fistül ile karıştırılabilir. Bu sebepten dolayı oroantral fistül kapatılması operasyonları öncesinde 
radyografik tetkikler ile UA gibi lezyonlar da ayırıcı tanıda göz önünde bulundurulmalıdır.

\section{KAYNAKLAR}

1. Robinson L, Martinez MG. Unicystic ameloblastoma: a prognostically distinct entity. Cancer. 1977; 40:2278-85.

2. Hsu M-H, Chiang M-L, Chen J-K. Unicystic ameloblastoma, Journal of Dental Sciences 2013; http://dx.doi.org/10.1016/j.jds.2012.03.028: 1-5.

3. Ackermann GL, Altini M, Shear M. The unicystic ameloblastoma: a clinicopathological study of 57 cases. J Oral Pathol. 1988;17:541-6.

4. Bisinelli JC, Ioshii S, Retamoso LB, Moysés ST, Moysés SJ, Tanaka OM. Conservative treatment of unicystic ameloblastoma. Am J Orthod Dentofacial Orthop. 2010;137:396-400.

5. Philipsen HP, Reichart PA. Unicystic ameloblastoma. A review of 193 cases from the literature. Oral Oncol. 1998;34:317-25.

6. Li TJ, Wu YT, Yu SF, Yu GY. Unicystic ameloblastoma: a clinicopathologic study of 33 Chinese patients. Am J Surg Pathol. 2000;24:138592.

7. Reichart PA, Philipsen HP, Sonner S. Ameloblastoma: biological profile of 3677 cases. Eur J Cancer B Oral Oncol. 1995;31B:86-99.

8. Nimonkar PV, Nimonkar SV, Mandlekar GP, Borle RM, Gadbail AR. Ameloblastoma arising in a dentigerous cyst: Report of three cases. J Oral Maxillofac Surg Med Pathol. 2014; 26:233-237.

9. Pogrel MA, Montes DM. Is there a role for enucleation in the management of ameloblastoma? Int J Oral Maxillofac Surg. 2009;38:807-12.

10. Lee PK, Samman N, Ng IO. Unicystic ameloblastoma--use of Carnoy's solution after enucleation. Int $\mathrm{J}$ Oral Maxillofac Surg. 2004;33:263-7.

11. Rosenstein T, Pogrel MA, Smith RA, Regezi JA. Cystic ameloblastoma-behavior and treatment of 21 cases. J Oral Maxillofac Surg. 2001;59:1311-6.

12. Lau SL, Samman N. Recurrence related to treatment modalities of unicystic ameloblastoma: a systematic review. Int J Oral Maxillofac Surg. 2006;35:681-90.

13. Altundal H, Duygu G, Arslan AH. Unikistik ameloblastoma: Vaka raporu. Atatürk Üniv Diş Hek Fak Derg 2006;16:66-9.

\section{Yazışma Adresi}

Gonca Duygu, DDS, PhD

Yeditepe Ünv.

Diş Hekimliği Fak.

No:238 Bağdat Cd 34728

Göztepe İstanbul.

Phone: +902163636044

Fax: +902163636211

Email: duygu_gonca80@hotmail.com 